\title{
Article
}

\section{Can Motivational Interviewing Make a Difference in Supporting Employees to Deal with Elevated Blood Pressure? A Feasibility Study at the Workplace}

\author{
Martina Michaelis ${ }^{1,2, *}$, Carmen Witte (née Farian) ${ }^{1}$, Barbara Schüle ${ }^{3}$, Katrin Frick ${ }^{4}$ and Monika A. Rieger ${ }^{1} \mathbb{D}$ \\ 1 Institute of Occupational and Social Medicine and Health Services Research, University Hospital of Tübingen \\ 72074 Tübingen, Germany; carmen.witte@posteo.de (C.W.); monika.rieger@med.uni-tuebingen.de (M.A.R.) \\ 2 Research Centre for Occupational and Social Medicine (FFAS), 79098 Freiburg, Germany \\ Occupational Health Service, Daimler AG, 70546 Stuttgart, Germany; barbara.schuele@daimler.com \\ 4 German Academy for Psychology, 10179 Berlin, Germany; info@psycho-login.eu \\ * Correspondence: martina.michaelis@med.uni-tuebingen.de
}

Citation: Michaelis, M.; Witte (née Farian), C.; Schüle, B.; Frick, K.; Rieger, M.A. Can Motivational Interviewing Make a Difference in Supporting Employees to Deal with Elevated Blood Pressure? A Feasibility Study at the Workplace. Int. J. Environ. Res. Public Health 2021, 18, 4179. https://doi.org/10.3390/ ijerph18084179

Academic Editors: Jukka Takala and Paul B. Tchounwou

Received: 9 March 2021

Accepted: 10 April 2021

Published: 15 April 2021

Publisher's Note: MDPI stays neutral with regard to jurisdictional claims in published maps and institutional affiliations.

Copyright: (c) 2021 by the authors. Licensee MDPI, Basel, Switzerland. This article is an open access article distributed under the terms and conditions of the Creative Commons Attribution (CC BY) license (https:/ / creativecommons.org/licenses/by/ $4.0 /)$.
Abstract: Background: To overcome the problem of a high prevalence of undiscovered or untreated arterial hypertension in people of working age, the effects of behavioral change counseling in occupational health $(\mathrm{OH})$ services should be investigated. The technique of motivational interviewing (MI) to support health-related lifestyle changes by physicians and/or occupational nurses ('health coach') has been shown to be successful in patients with chronic diseases. In 2010, we planned a randomized controlled trial (RCT) with employees who suffer from mild arterial hypertension. A preliminary feasibility study was performed in a large manufacturing company in Germany. Methods: All employees with elevated blood pressure measured by the $\mathrm{OH}$-service were invited to undergo validation by 30 self-measurements. Persons with validated elevated values and without medical treatment received either usual hypertension counseling (control group, CG) or intensified MI-counseling (intervention group, IG) by the occupational health physician. Subsequently, the IG received MI-support from the 'health coach' in four telephone counseling sessions. Assessed feasibility factors included organizational processes, the acceptance of the validation procedure and the MI-counseling, and as primary outcome for an RCT the extent to which participants made health-related changes to their lifestyles. Results: Initially, 299 individuals were included in Study Part A (screening). At the end of Study Part B (intervention), out of 34 participants with validated and nontreated mild hypertension, only 7 (IG) and 6 (CG) participants completed the intervention including documentation. The high drop-out rate was due to the frequent lack of willingness to perform the 30 self-measurements at home with their own equipment. Acceptance was little higher when we changed the method to two repeated measurements in the $\mathrm{OH}$ service. MI-counseling, especially by the health coach, was evaluated positively. Conclusions: Despite the promising counseling approach, the feasibility study showed that an RCT with previous screening in the operational setting can only be implemented with high financial and personnel effort to reach an appropriate number of subjects. This substantial result could only be achieved through this comprehensive feasibility study, which investigated all aspects of the planned future RCT.

Keywords: arterial hypertension; motivational interviewing; behavioral change counseling; occupational health service; health coach; feasibility study

\section{Introduction}

Arterial hypertension is a significant risk factor for cardiovascular diseases, especially for strokes and heart attacks, and thus a major health problem in the population. In Germany, between one quarter and one third has known medically diagnosed high blood pressure [1-3]. The high prevalence of undetected arterial hypertension [4,5], especially in 
younger men [6], is a health care problem. Screening studies in different workplace environments and countries identified a prevalence of arterial hypertension ranging between $10 \%$ and $40 \%$ [7-12]. In the German car industry this was even as high as $75 \%$ (men) and $47 \%$ (women) [13].

Further, rates of unawareness of the condition were, for example, $24 \%$ in Canada and $44 \%$ in Hungary [9]. In a French workplace study, this concerned almost half of the men and three quarters of the women diagnosed with hypertension [10]. In a younger German study, $13 \%$ of $n=67$ subjects were unaware of their condition [11].

Facing the forthcoming demographic development, it is to be expected that employees must remain efficient and healthy even longer than before to remain a necessary link in the chain of employability [14]. This also places an increasing responsibility on employers and their occupational health services to intensify workplace health promotion activities for aging workers. In addition, employees appreciate an employers' commitment to maintaining their health [15].

Besides primary care services, occupational health $(\mathrm{OH})$ services are ideal for screening for such conditions, as they come into contact with clients during regular check-up consultations or acute care situations who normally may not have regular contact with a health care provider, e.g., younger men.

Further, support in implementing health beneficial lifestyles is one of the pillars of the WHO Healthy Workplace Model $[16,17]$. While implementing screening measures in the daily routine of German occupational health physicians seems possible without major effort [18-21], in Germany, only few intervention studies have been carried out in the occupational setting so far $[12,18,20,22-24]$.

Mild arterial hypertension does not necessarily require medical treatment; it is amendable to lifestyle interventions, such as increased physical activity and weight reduction, improved nutrition and moderation of alcohol consumption, salt restriction and smoking cessation [25]. On the other hand, adhering to regular blood pressure measuring protocols as well as implementing and maintaining lifestyle changes are easier to achieve with further support $[26,27]$.

Numerous possibilities have been studied to achieve these changes, as the American Heart Association summarized in a scientific statement: Incentives or motivational interviewing as evidence-based methods can support patients in implementing physical activity and dietary lifestyle changes, in addition to other options, such as goal setting, self-monitoring, and prolonged contact between patients and healthcare professionals [28].

Motivational interviewing (MI) as an approach of behavioral change counseling $[29,30]$ was first developed for addiction counseling [31]. Since the 1990s, MI has also been used in the treatment of chronic diseases, such as cardiovascular diseases, overweight, hypertension, or diabetes mellitus [32,33]. The goal of the directive client-centered counseling approach is to support behavior change in people who feel ambivalent about changing certain behaviors [34] and to build intrinsic motivation to change one's own behavior. This should be achieved by exploring and resolving ambivalence. Ambivalence is expressed by clients' statements for or against change: 'change talk' or 'sustain talk'. Client speech predicts client outcome and is associated with MI-adherent or non-adherent counseling behavior [35]. MI has also been used in different settings, such as hospitals [36,37] and primary care for conditions such as chronic pain management, physical activity, and obesity management [38].

Studies evaluating lifestyle counseling in the occupational setting were rare when we initiated our study [22,39-44]. However, study designs differed in two RCTs, two cluster-RCTs, one CT, and two observational studies (non-(R)CTs): Either only physicians were involved in lifestyle counseling, but not health coaches [22,40,41], or the MI concept was not always involved [22]. The number of consultations was also not always fixed, but, e.g., depended on the assessment of the attending physician [40]. In addition, there was not always comprehensive health-related lifestyle counseling, but rather a focus on single health problems, such as alcohol addiction $[41,42,44]$. The health coach concept was 
pursued in four studies. All of them offered counseling by external protagonists [39,42-44], which was considered feasible and successful.

Up to now, evidence of the effectiveness of counseling to change health-related behavior has increased. This concerns individuals with cardiovascular risks [45-47], work-related stress [48], musculoskeletal disorders [49], or with diverse other noticeable health-related risks [50,51].

MI has not only been delivered successfully in face-to-face settings, but also as a telephone-based counseling approach [52-54]. MI can be delivered by trained personnel from a variety of professional backgrounds [33]. Good experiences were reported in studies in which medical assistant staff counseled patients at risk for cardiovascular diseases [55-57]. Three studies found in the occupational health service setting $[46,47,51]$ showed partial effects on lifestyle changes.

Based on the positive experiences of the studies mentioned above, it can be assumed that support for lifestyle changes also works for employees with mild arterial hypertension when MI counseling techniques are implemented by occupational health physicians and subsequently by a so-called 'health coach' as an alternative to immediate drug treatment. Against this background, the authors planned a feasibility study starting in the year 2010 prior to a future randomized controlled trial (RCT) with the primary outcome 'extent to which health-related lifestyle has changed' in terms of eating habits and/or sporting activities.

A single measurement is considered insufficient to identify persons whose blood pressure values are not only temporarily elevated, and might be the result of a so-called 'white coat effect' [58]. Thus, the initial value must be confirmed. The gold standard recommendation is a 24-h long-term measurement [59]. However, this procedure is not suitable for the operational setting, given the expected demand for measuring devices. Alternatively, the Austrian Society for Hypertension recommends 30 home self-measurements, of which at least seven must be elevated to allow for a corresponding diagnosis [60]. However, there is no internationally recognized gold standard for home blood pressure measurements [61].

The goal of this feasibility study was to evaluate important parameters such as acceptability and practicable methods of blood pressure measurements, promoting and hindering factors at the level of subjects and organization, and the acceptance of the MI intervention indicated by the number of willing participants to estimate likely recruitment rates of subjects and response rates to follow-up. Here we present the feasibility study and discuss the most important results.

Following the relevant recommendations for complex interventions [62-64], we investigated the following research questions:

1. How many employees with so far unidentified or uncontrolled hypertension who have not yet started medical treatment can be identified in the occupational health service of a large manufacturing company as a database for further interventions?

2. How many of the identified employees can be motivated to undergo validation after positive screening for elevated blood pressure? How many of them will perform further self-assessments to validate their initially elevated blood pressure value? What are promoting and hindering factors?

3. How many employees with validated elevated blood pressure can be motivated to undergo hypertension prevention counseling in the occupational health service? How many are willing to be randomized? How many are willing to be subsequently supported by the health coach, and at least how many complete the intervention?

4. Which factors inhibit or support the implementation of motivational interviewing in the occupational health setting?

5. Are the evaluation instruments feasible? How many participants complete all questionnaires up to the end of the study?

6. How do German occupational health physicians and study participants assess the motivational interviewing approach? When we designed the study in 2010, to our knowledge, motivational interviewing had not been used regularly in the occupa- 
tional health sector to affect employees' behavior in Germany, with the exception of an alcohol use intervention program.

The study was approved by the ethics commission of the medical faculty of the Eberhard Karls University of Tübingen (329/2010BO1). This manuscript follows the recommendations for reporting on feasibility studies of the CONSORT group [65].

\section{Materials and Methods}

\subsection{Study Part A (Methods of Screening and Validating Hypertension)}

All employees who, planned or in the event of an emergency, visited the occupational health service between October 2010 and April 2011 underwent a blood pressure measurement using the Riva-Rocci (RR) method. Recruiting staff were physician assistants, laboratory personnel and staff of the emergency department.

After informed consent, employees with values between 140/90 and 159/99 $\mathrm{mmHg}$ were asked to take part in Study Part A with 30 repeated domestic self-measurements with their own equipment. The equipment could be obtained at a reduced price from the occupational health service (OHS), if necessary, and were required to have a seal of approval from the German High Pressure League (Deutsche Hochdruckliga) [66].

We calculated 50 persons with complete follow-up data for intervention and control groups, respectively. During previous $\mathrm{OH}$ service screenings, an average of seven employees with elevated blood pressure values between $140 / 90$ and 159/99 $\mathrm{mmHG}$ ( $8 \%$ on all examination occasions) were found per working day, mostly subjects without medical treatment. Under the (unfavorable) assumption that only a quarter of the employees could be recruited to participate in a fully completed study, four recruitment months were calculated.

To increase the return rate of the completed documentation, a maximum of three telephone reminder attempts were made after the agreed return period was exceeded. Recruiting for this kind of validation started in February and ended in April 2011.

Due to the low willingness of the employees to participate in this kind of selfmeasurement (see results section), we changed the validation procedure to two repeated measurements in the $\mathrm{OH}$ service between February and April 2011. A median of $\geq 140 / 90 \mathrm{mmHg}$ of the total of three values confirmed the suspected arterial hypertension. This fulfilled the requirements documented in guidelines for repeated monitoring of elevated blood pressure values to confirm the diagnosis. However, there is no indication in available studies that two repeated blood pressure measurements are sufficient to confirm the diagnosis of arterial hypertension. We were aware of that, yet we considered this a feasible procedure for the $\mathrm{OH}$ setting.

The blood pressure values measured at home were documented by the study participants themselves using a 'blood pressure card'. The values measured in the $\mathrm{OH}$ service were documented similarly by the staff. The documents for the self-measurements were handed out in the $\mathrm{OH}$ service and sent back through the internal postal service of the enterprise using closed envelopes to secure confidentiality.

If the values continued to be slightly elevated between $140 / 90$ and $159 / 99 \mathrm{mmHg}$, the respective employees received an invitation to an individual hypertension prevention counseling. Exclusion criteria for participation can be found in Online Supplementary Table S1.

For ethical reasons, usual care counseling was also offered to employees who were not invited to the intervention due to exclusion criteria. Employees with highly elevated blood pressure ( $\geq 160 / 100 \mathrm{mmHG}$ ) were motivated to visit their primary care physician or a medical specialist. Further developments and results of the adherence to this recommendation were evaluated separately as part of a medical doctoral thesis [67].

\subsection{Study Part B (Intervention Methods)}

Employees with verified hypertension values were informed about the results of the repeated blood pressure measurements by at least three telephone attempts and in the case 
of unavailability by a subsequent letter. If the inclusion criteria were met (slightly elevated blood pressure between 140/90 and 159/99 $\mathrm{mmHg}$ ), they were invited to participate in the study and, if interested, were given an appointment for counseling with an $\mathrm{OH}$ physician. Even if the employees were not interested, they were offered usual care hypertension counseling by another company physician.

Shortly before counseling, study participants were given detailed information at the OHS. After giving informed consent, participants were randomly assigned to either the intervention group (MI-counseling by an occupational health physician (OHP) at time T0 and subsequently by the health coach) or the control group (usual care counseling by an OHP) using single blinded block randomization (block size $n=4$, freeware tool Research Randomizer).

Four physicians and the health coach were trained by an expert in behavioral change counseling using MI during an interactive one-day workshop. The basic documents for consultation and documentation were developed with the support of another expert (KF) $[68,69]$.

The objectives of the health-related lifestyle counseling for the intervention group were an evidence-based expansion of health-related knowledge and the ability to self-manage based on the MI-principles and attitude ('MI-spirit'). These principles are empathy and respect for the autonomy of the patient/volunteer, enhancing intrinsic motivation, focusing on the client's goals, developing discrepancy between clients' goals or values and their current behavior, and exploring ambivalence, as well as supporting self-efficacy. Reflective listening helps to recognize and evoke 'change-talk'. Using MI-methods, individual health goals were developed mainly from the subject areas of nutrition and physical exercises (see process shown in Figure 1).

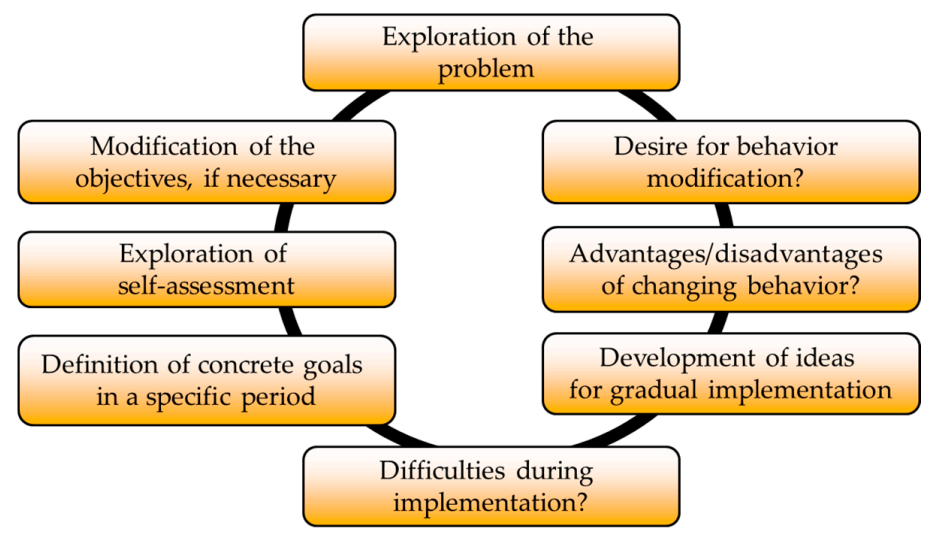

Figure 1. Procedure and content of motivational interviewing (MI)-counseling in the intervention group. Legend: Representation based on Information from [68] and adapted from [70].

The intervention group was informed by the MI-trained occupational health physician about risk factors for developing arterial hypertension and possible lifestyle changes regarding a healthier diet, more exercise, (better) stress management strategies, but also abstaining from smoking. The so-called Score Germany table was used to illustrate the overall cardiovascular risk and possible effects of behavioral changes [71].

The control group received usual care in the form of less intensive counseling by the same four occupational health physicians. The MI-related documents developed by our group were used as the basis for counseling the intervention group, and the standard $\mathrm{OH}$ service documents were used for counseling the control group.

Finally, both groups received a hypertension prevention brochure designed by their employers' workplace health promotion department and were informed in detail about in-house and external health promotion offers and motivated to participate.

Subsequently, an MI-trained medical student (CW) acted as health coach for the intervention group and accompanied the implementation of individual health goals established 
during counseling with the $\mathrm{OH}$ physicians into concrete, realistic steps. This was carried out by four counseling sessions via telephone during the employees' leisure time. Intervals between the contact times $\mathrm{T} 1$ through $\mathrm{T} 4$ were as follows: $\mathrm{T} 1=\mathrm{T} 0+$ one week, $\mathrm{T} 2=\mathrm{T} 1+$ one week, $\mathrm{T} 3=\mathrm{T} 2+$ three weeks, $\mathrm{T} 4=\mathrm{T} 3+$ four weeks.

\subsection{Evaluation Methods and Instruments}

The feasibility of both screening and intervention was assessed in a mixed-method design following the dimensions process and outcome evaluation according to Donabedian [72]; see Online Supplementary Tables S2 and S3; all evaluation instruments were developed by the authors. Experiences within the recruiting processes were collected in protocols and semi-standardized group and expert interviews with the $\mathrm{OH}$ service staff.

Experience and satisfaction with hypertension prevention counseling in the $\mathrm{OH}$ service was rated in a standardized questionnaire by all participants six months after the $\mathrm{OH}$ physician consultation at T5 (i.e., T4 + nine weeks). The experience of counseling by the health coach was evaluated only by the intervention group.

To assess lifestyle changes as a primary outcome, a standardized questionnaire was deployed at baseline (T0) and T5 (final evaluation), aiming to compare data on dietary habits, exercise behavior, and nicotine consumption. The assessment of the subjectively rated lifestyle changes at $\mathrm{T} 5$ included six items that were combined into a standardized sum score.

Secondary outcomes at $\mathrm{T} 5$ were blood pressure values, the general expectation of self-efficacy, self-assessed health, and the importance of own goals, self-confidence, and readiness to work toward these goals. Details of Outcomes and evaluation methods can be derived from Online Supplementary Tables S2 and S3.

\subsection{Statistical Analysis}

Results from standardized questionnaires are presented descriptively by percentages or mean values/standard deviations (SD)/median. Cross-sectional group differences were analyzed by $\mathrm{Chi}^{2}$ and nonparametric Mann-Whitney U tests. Significance threshold value was set to $p=0.05$ (Study Part A) and $p=0.10$ (Part B due to low sample sizes). The respective effect sizes correlation coefficient phi and $\mathrm{r}(\mathrm{z} / \operatorname{root}(n))$ were categorized with low $(<0.3)$, moderate $(0.3-0.5)$ and high $(>0.5)$ [73].

For Part A (validation of blood pressure measurements), the examination of individual predictors on the outcome 'willingness to participate in repeated measurements' was analyzed exploratively, as the sample was large enough for multivariate logistic regression (the respective effect size was odds ratio with 95\% confidence interval). Based on the simultaneous inclusion of all previously bivariate-tested variables, which showed $p<0.20$ $($ method $=$ 'enter'), nine predictor variables were tested (see Online Supplementary Table S4).

\section{Results}

\subsection{Study Part A (Screening and Validation of Hypertension)}

3.1.1. Results of Outcome Evaluation: Number of Individuals with Mild Hypertension

The study period during which validation of the initial measured blood pressure values was performed with 30 self-measurements lasted five months; $n=203$ followed the invitation for blood pressure validation. This period lasted an additional two months for the subsequent 2RM group $(n=96)$. During that time, a total of 299 employees with initially elevated blood pressure values were identified among $n=2181$ who took part in the screening. Out of these, $90.3 \%$ were men and $66.1 \%$ were employed in production or production-related areas. The mean age was 45.3 years (standard deviation SD 9.0).

In total, less than half of the participants were aware of diagnosed hypertension ( $n=119 / 299 ; 39.7 \%$; see additional information in Figure 2). Especially in the high blood pressure group, only one out of five individuals was undergoing medical therapy at the time point of the initial screening $(20.2 \% ; n=35$ out of 173$)$. 


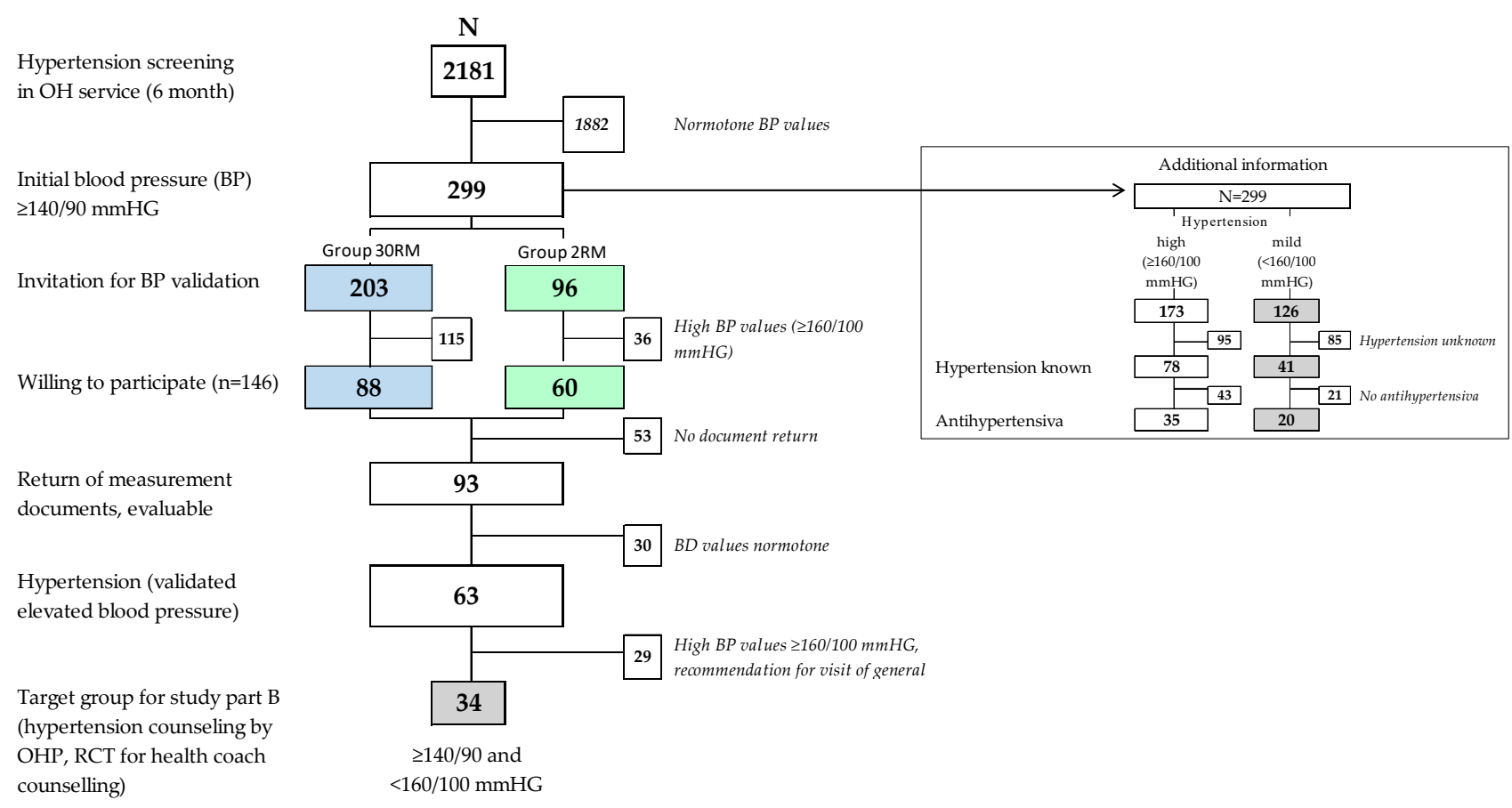

Figure 2. Participants in Study Part A (screening and hypertension validation).Grey shadowed values = employees with slightly elevated blood pressure values $(\geq 140 / 90$ and $<160 / 100 \mathrm{mmHG})$. Abbreviations: $30 \mathrm{RM}=$ group with 30 repeated self-measurements; 2 RM = group with 2 repeated measurements in the occupational health service; OHP = occupational health physician; OHS = occupational health service.

\subsubsection{Results of Process Evaluation: Feasibility of Screening with Focus on Employees}

The willingness of employees with initially elevated values to participate in repeated blood pressure measurements was slightly lower in group 1 (30 RM) than in group 2 ( $2 \mathrm{RM}$ ) with two repeated measurements in the $\mathrm{OH}$ service $(43.3 \%$ vs. $63.5 \% ; p=0.001$; phi $=0.2 ; n=88 / 203$ vs. $60 / 96$ ). The individual results of blood pressure measurements were documented on so-called blood pressure cards, yet these were not returned reliably in either group, with a lower rate in group 1 than in group 2 (49/88 vs. 39/60, not significant). The necessity of telephone reminders to submit results was also significantly greater for group 1 than for group $2(69.4 \%$ vs. $25.6 \% ; n=34 / 49$ vs. $n=10 / 39)$.

A completed blood-pressure card was evaluable from a total of 88 participants $(59.4 \%)$ out of the $n=148$ who agreed to undergo validation (see again Figure 1; no statistical differences between validation groups).

The most important reasons for not participating in the validation measurement procedure were lack of interest, the time required for the procedure, and existing medical treatment. There were no statistical group effects (see Online Supplementary Table S5).

The results of the multivariate regression analysis showed that the willingness to participate was twice as high in group 2 (2 RM) compared to group 1 (30 RM); OR = 2.1, $\mathrm{CI}_{95 \%}=1.2-3.6$. Willingness to participate was 50\% lower for employees with current antihypertensive medication and for employees working in production compared to the reference group 'administration' (both $\mathrm{OR}=0.5, \mathrm{CI}_{95 \%}=0.2-0.9$ and $0.3-0.9$, respectively).

The lowest participation rate was estimated for employees working in production with previous medical therapy in group 1 (see Online Supplementary Figure S1). All variables were statistically significant in the model except for age, which was slightly below the threshold for significance $(p=0.051)$. No predictive value was found for blood pressure level at the initial measurement, the profession of the recruiting person in $\mathrm{OH}$ service for the initial measurement, the reason for visiting the $\mathrm{OH}$ service, knowledge of previously diagnosed hypertension, or gender. 


\subsubsection{Results of Process Evaluation: Feasibility of Screening with Focus on OH Service}

In general, all documentation sheets within the study process were completed without gaps and were found to be suitable by $\mathrm{OH}$ service personnel.

Detailed results of the group interview with four medical assistants to evaluate the recruiting process are presented in Online Supplementary Table S6. In summary, it was considered possible to integrate the recruitment interviews into the daily work routine, but the high proportion of employees with poor language competence generated problems. In addition, skepticism about data protection issues were reported, as well as reluctance to participate after initial interest due to the effort associated with repeated domestic measurements in the group with 30 repeated blood pressure measurements (30 RM). Improvements proposed for the study process included forgoing the 30 domestic measurements in favor of two repeated measurements in the $\mathrm{OH}$ service practice, multilingual study information, and visually attractive brochures.

\subsection{Study Part B (Intervention)}

3.2.1. Feasibility of RCT Design and of Hypertension Counseling by OH Physicians (Focus on Participants)

From 62 participants with validated elevated blood pressure (see again Figure 2), a target group of $n=35$ with mild hypertension $(\geq 140 / 90$ and $<160 / 100 \mathrm{mmHg}$ ) remained for randomization, followed by additional counseling by the health coach (IG), or no additional counseling (CG). In total, $n=26$ were reached for invitation and were randomized prior to the counseling date (see Figure 3). Similar to Study Part A it was time-consuming to reach the employees in shift work to inform them about verified hypertension results and invite them to receive counseling by the $\mathrm{OH}$ physician.

Validated blood pressure $\geq 140 / 90$ and $<160 / 100 \mathrm{mmHG}$, target group for hypertension counseling by $\mathrm{OHP}$

Reached for invitation for OHP-counseling

Willingness for OHP-counseling

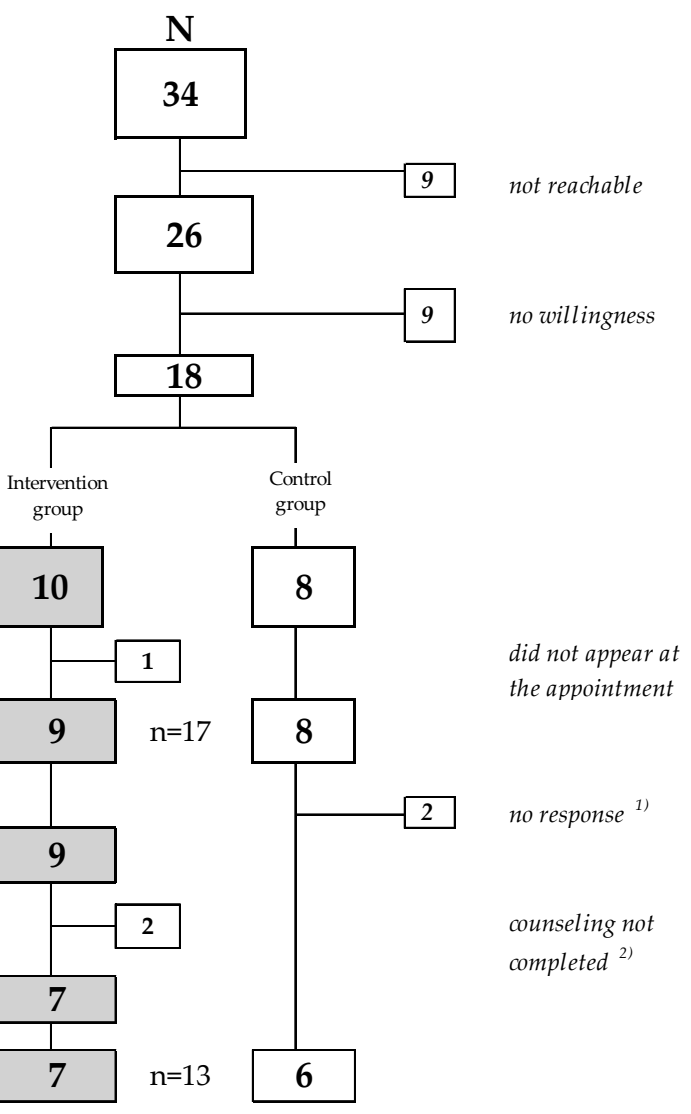

Figure 3. Participants in Study Part B (intervention with randomized controlled trial (RCT) study design). Legend: ${ }^{1)}$ to complete $\mathrm{T} 5$ questionnaire after telephone reminder; ${ }^{2)}$ not reached any more. 
$n=18$ were invited to the health coach counseling and $n=13$ completed this counseling. The end of Study Part B reached 13 participants (IG: $n=7$, CG: $n=6$ ) out of the target group.

During counseling in the intervention group, the self-assessment of the importance of own goals was high (median 7.8, with a possible range from 1 'not at all' to 10 'very much'), self-confidence was medium (median 6.0), and readiness to work for these goals relatively low (median 4.0; cases answering to the three items: $n=9 / 9 / 7$ ).

IG and CG assessments of MI-counseling by the OHP resulted in mean values of 2.14 (SD 1.17) and 2.38 (SD 1.19; sum score; possible range from 1 'fully applies to 5 'applies not at all'), respectively. The respective mean satisfaction score was 1.82 (SD 1.20) in IG and 2.54 (SD 1.05) in CG. No statistical differences or positive effect sizes were found $\left(\mathrm{r}_{\text {sum score }}=0.05\right.$ and $0.03 ; p=0.534$ and 0.295$)$. More details are presented in Online Supplementary Table S7.

3.2.2. Feasibility of Study Processes and OHP Counseling-Assessment of $\mathrm{OH}$ Physicians (Focus on Own Work)

The median duration for the behavioral change counseling was 25 min in the intervention group and $17 \mathrm{~min}$ for the usual counseling in the control group, respectively. All documentation forms about communicating individual topics in lifestyle counseling were completed without gaps and found to be suitable by the OHPs.

The median sum scores of satisfaction with the MI-method and respective procedures were 2.92 with a range from 1 'very satisfied' to 5 'not satisfied at all' (satisfaction with the concept of motivational interviewing), 2.25 (satisfaction with familiarization with the study design, 2.25 (satisfaction with communication processes in the study team and the complex documentation procedure), but only 4.50 for 'satisfaction with the integration of MI into the daily work routine' (see Online Supplementary Table S8).

3.2.3. Feasibility of Repeated MI-Counseling by the Health Coach (Focus on Participants; IG Only)

The telephone calls lasted on average $20 \mathrm{~min}$ (range 5 to $40 \mathrm{~min}$ ). During counseling, the seven participants in the intervention group seemed to be highly motivated. This is also reflected:

- In the 12-item sum score concerning assessment of and satisfaction with the concept (median 3.7, ranging from, 1 'fully applies to 5 'not applies at all' (see Online Supplementary Table S9);

- In the oral feedback during the four health coach MI-counseling sessions. The selfassessment of importance of own goals (median 7.3-10.0 from T1 to T4 with a possible range from 1 'not at all' to 10 'very much'), self-confidence (median 4.0-8.8), and readiness to work for these goals (median 8.0-10.0).

\subsubsection{Intervention Effect on Primary Outcome 'Lifestyle Changes'}

(a) RCT group comparison; $n=7$ IG, $n=6$ CG; T5 6 months after baseline evaluation: There was a moderate, but due to the small sample size statistically non-significant improvement in the primary outcome 'lifestyle changes' as an overall score of 0 'not at all' to 4 'very strong' compared to the control group $\left(\mathrm{r}=0.49\right.$; mean value ${ }_{(\mathrm{IG})}=4.43, \mathrm{SD} 0.54$, range 4-5; mean value (CG) $=4.00$, SD 0.00, range $4-4$, median both 4.0 ).

The three smokers in IG reduced their nicotine consumption slightly with a tendency towards moderate effects compared to four smokers in CG $(\mathrm{r}=0.28$; mean value (IG) $=2.67$ (SD 2.31), mean value $(C G)=1.00$ (SD 2.00), median both 4.0, range both 0-4.

\subsubsection{Intervention Effect on Secondary Outcomes at $\mathrm{T} 5$}

At T5, four out of seven persons in IG indicated having achieved their previously defined personal goals.

All six persons in IG and five out of seven persons in CG reported that they continued measuring their blood pressure from time to time at T5. The two other CG subjects 
stated that they did not have an own measurement device. The blood pressure card was available from $n=5$ (IG) and $n=3$ (CG). Due to the small number of cases, we waived the statistical evaluation.

\section{Discussion}

We present results of a feasibility study performed prior to a future randomizedcontrolled effectiveness study between 2010 and 2011. It was planned to focus on the effect of behavioral change counseling concerning a healthy lifestyle among employees with validated mild hypertension and without previous drug therapy. We used the motivational interviewing method, which is considered to be successful in different patient groups. One of the aims of the feasibility study was to apply the method for secondary prevention in the occupational health service setting with persons who generally are little motivated to visit their general physician for prevention, e.g., due to their gender (men) or age (younger) and thus to their general health status.

The novelty in this study was the counseling provided by a combination of MI-trained occupational health physicians plus a perpetuating MI-trained health coach. As described above, only a few studies could be found when we started our project in 2010. Since then, seven counseling studies have been published which address the occupational setting's ability to support behavioral lifestyle change, with diverse study designs [45-51]. In two RCTs, two cluster-RCTs, and three observational studies, counseling was again performed exclusively by physicians, $[45,47,49]$ or by team leaders or other staff $[48,50]$. Only the study by Groeneveld et al. [46] is more or less comparable to our design, since the counseling was conducted by occupational health physicians and an occupational nurse.

Further, newer counseling study designs vary in terms of the intensity of MI-counseling (one-time [50], variable number of consultation units [49], higher intensity compared to our study [46,47]). In addition, only partial MI-elements were used instead of the entire MI-concept $[46,50,51]$, or counseling to support behavioral lifestyle change took place without motivational interviewing techniques [45], or group intervention was used instead of individual counseling [48]. Interventions were related to comprehensive health-related lifestyle aspects to prevent cardiovascular risks [45-47,51], motivation to take advantage of well-being programs [50], physical activities and relaxation to reduce stress-related need of recovery [48], or the adherence to therapy recommendations of rehabilitation patients for a faster return to work [49]. None of these studies focused on hypertension as a primary approach. However, positive effects were reported in half of the newer studies, except for no effects in one study [47] and only partial effects in two other studies [46,51].

Our results also show that validating a single elevated blood pressure value using 30 self-measurements instead of the gold standard 24-h continuous measurement was too much effort for our subjects. The participants lost motivation over the four-month period, which subsequently led to a high drop-out rate.

Further, the requirement of participants to finance the measuring device themselves might have caused a selective sample of "willing to pay". It can be assumed that making measuring devices available free of charge would have led to a higher level of acceptance; however, this would have been beyond the scope of what is feasible for an employer.

Acceptance was increased using a simplified validation procedure; this was reached using only two repeated blood pressure measurements, which is beyond the gold standard for validating an initially elevated blood pressure value. On the other hand, this proved to be a feasible procedure for the OHS setting [70]. The procedure was discussed with Seibt et al., who in the $1990 \mathrm{~s}$ identified a minimum of 15 self-measurements on three days as sufficient diagnostic confidence [74]. To rule out false diagnoses effectively, the authors currently recommend repeated self-measurements completed by a 24-h measurement [75], which is even more costly for employees and therefore does not seem feasible for a project in the vocational setting.

Since our feasibility study also showed that many employees with elevated measured values during the screening preferred to consult their general practitioner, consideration 
should be given to how the hypertension validation can be successful under consideration of general medicine (see the study by Randerath et al. [11]). However, the participation rate in this study was also low.

Regarding study procedures, the screening itself was feasible; potential for improvement was only evident in minor cases. On the other hand, the effort required to complete the survey instruments and telephone contact with employees working in shifts was enormous, which would have to be accounted for in personnel cost planning for an effectiveness study.

Given the small number of cases, the positive effects on the primary outcome 'lifestyle changes' in our intervention study (Part B) were not statistically significant. However, associated moderate effect sizes show that the partial effects found in comparable, more recent studies $[46,47,51]$ could also be confirmed with a larger sample.

\section{Strengths and Limitations of the Study}

The strengths of the study lie in the comprehensive assessment of the feasibility of all aspects of a future (cluster-)randomized-controlled effectiveness study. Besides the proof of feasibility and value of MI counseling with small case numbers in the setting of an occupational health service, and implementation of two different regimes for validation of initially elevated blood pressure, one of the main results described the high effort necessary for the future effectiveness study. Chances and limits of a future, as yet unplanned RCT, as well as practical suitability beyond study conditions can be derived from our feasibility study.

Limitations: We refrained from estimating the willingness to participate in the screening part of the study (i.e., validation of the elevated blood pressure reading) in a small sample prior to the presented feasibility study. In addition, the study results were generated in a large company with a centrally located in-house $\mathrm{OH}$ service. Transferring the design to companies with an in-house but spatially distant or external $\mathrm{OH}$ service seems to be possible only to a limited extent. The participants in the randomized-controlled part of the study comparing both counseling methods may be a positive selection, as only the employees who performed validation of the blood pressure measurement were asked to participate in Part B of the study. A meaningful analysis of intervention effects was not possible due to the small number of intervention cases.

There was no evaluation of MI-adherence of counsellor behavior to assess quality and integrity of the MI-interventions [76].

\section{Conclusions}

To our knowledge, this feasibility study is one of few with a randomized-controlled design that also includes the complete MI concept to counsel employees with an initial chronic health problem by occupational health physicians and a company health coach. Undetected slightly elevated blood pressure is symptom-free and thus the level of suffering and the subjective need for lifestyle behavior change is low. Therefore, we conclude that the intended optimization of health in younger employees of our study design has an unbalanced cost-benefit ratio.

Even though the motivation of those who could be recruited for the intervention was recognizably high, an effectiveness study (i.e., an RCT or $\mathrm{CRCT}$ ) according to the described design would be feasible, but expensive and time consuming. Further, the high effort in recruiting affected persons appears not to be practicable beyond study conditions.

Further, following the results of Jarbøl et al., people with health problems seem to change their lifestyle rather than take medication to reduce cardiovascular risks-at least intentional [77]. Therefore, the importance of counseling by the occupational health service to avoid harmful behavior should not be underestimated. This would allow a long-term relationship to be built up with young, high-risk individuals who are not yet suffering from health problems, and the motivation for health-related changes in behavior can be worked on.

Future RCTs should assess MI-adherence of counseling behavior. 
Supplementary Materials: The following are available online at https: / www.mdpi.com/article/ 10.3390/ijerph18084179/s1, Online Supplementary Table S1: Exclusion criteria for participation in study part A (blood pressure screening), Table S2: Outcomes and evaluation methods in Study Part A (screening), Table S3: Outcomes and evaluation methods in Study Part B (intervention), Table S4: Predictor variables on the outcome 'willingness to participate in repeated measurements' (study part A), Table S5: Reasons for non-participation by type of validation measurement-results of recording at first contact in a semi-standardized process protocol (multiple answers), Table S6: Answers of medical assistant staff concerning experiences recruiting employees for participation in study part A (screening); group interview (4 out of 5 persons; multiple answers possible), Table S7: Occupational health physicians' hypertension prevention counseling -assessment and satisfaction of participants of intervention and control group, Table S8: Satisfaction with the MI-method and respective procedures from the point of view of the occupational health physicians $(n=4)$, Table S9: Experiences with the telephone MI-counseling by the health coach (intervention group), Figure S1: Participation in hypertension validation by work area, treatment status, and validation type.

Author Contributions: All authors contributed significantly to the study design, the study implementation, data analyses, and interpretation, as well as the writing of the manuscript; M.M., B.S. and M.A.R. developed the study design and K.F. gave valuable support to all MI-related aspects within the design; M.M. conducted the surveys and performed the statistical analysis; C.W. organized the recruitment, recorded process observations, performed expert and group interviews, and worked as 'health coach' receiving valuable feedback by K.F.; as leading occupational health physician, B.S. organized all processes in the Occupational Health Service; M.M., B.S., C.W. and M.A.R. interpreted the results; M.M. and M.A.R. wrote the manuscript with substantial input by C.W., B.S. and K.F., they also critically reviewed the manuscript. All authors read the final manuscript and approved it for publication. The study is part of the doctoral thesis of Carmen Witte at the Medical Faculty of Tübingen University. All authors have read and agreed to the published version of the manuscript.

Funding: This study was financed by own resources and by the kind financial support of the statutory company health insurance Daimler BKK, Bremen, Germany. We acknowledge support for the APC by Open Access Publishing Fund of University of Tübingen.

Institutional Review Board Statement: The study was conducted according to the guidelines of the Declaration of Helsinki, and approved by the Ethics Commission of the Medical Faculty of the Eberhard Karls University of Tübingen (329/2010BO1).

Informed Consent Statement: Informed consent was obtained from all subjects involved in Study Part A and Study Part B of the feasibility study.

Data Availability Statement: The data presented in this study are available on request from the corresponding author.

Acknowledgments: The authors thank Sarah Hudak and the study team of 'YourBloodPressureCheck' in the $\mathrm{OH}$ service for their dedicated assistance during this study. We also thank Daniela Kempkens for her assistance in writing the introduction. The work of the Institute of Occupational and Social Medicine and Health Services Research is supported by an unrestricted grant from the Employers' Association of the Metal and Electric Industry in Baden-Württemberg (Südwestmetall), Germany.

Conflicts of Interest: M.M., C.W., B.S. and M.A.R. declare no conflict of interest. K.F. teaches MItechniques to physicians and other health care professionals.

\section{References}

1. Diederichs, C.; Neuhauser, H. Regional variations in hypertension prevalence and management in Germany: Results from the German Health Interview and Examination Survey (DEGS1). J. Hypertens. 2014, 32, 1405-1413. [CrossRef] [PubMed]

2. Grobe, T.G.; Steinmann, S.; Szecsenyi, J. Physicians' Report 2019 (In German: Arztreport 2019); Series of Publications on Health Analysis; Barmer Health Insurance: Berlin, Germany, 2019; Volume 14, ISBN 978-3-946199-20-5.

3. Schneider, M.; Scholl, J. Analysis of the current health status of middle-aged persons. Preliminary results of a cross-sectional survey of employees aged 40 to 65 years in a pharmaceutical company (In German: Analyse des Aktuellen Gesundheitsstatus bei Personen im Mittleren Lebensalter: Erste Ergebnisse einer Querschnitterhebung bei Mitarbeitern zwischen 40 und 65 Jahren in einem pharmazeutischen Unternehmen). Arbeitsmed. Sozialmed. Umweltmed. 2007, 42, 596-604. 
4. $\quad$ Löwel, H.; Meisinger, C.; Heier, M.; Hymer, H.; Alte, D.; Völzke, H. Epidemiology of hypertension. Selective results of populationrepresentative studies in Southern and Northern Germany (In German: Epidemiologie der arteriellen Hypertonie in Deutschland). Dtsch. Med. Wochenschr. 2006, 131, 2586-2591. [CrossRef] [PubMed]

5. Lacruz, M.E.; Kluttig, A.; Hartwig, S.; Löer, M.; Tiller, D.; Greiser, K.H.; Werdan, K.; Haerting, J. Prevalence and Incidence of Hypertension in the General Adult Population. Results of the CARLA-Cohort Study. Medicine 2015, 94, e952. [CrossRef]

6. Chen, R.; Tunstall-Pedoe, H.; Morrison, C.; Connaghan, J.; A'Brook, R. Trends and social factors in blood pressure control in Scottish MONICA surveys 1986-1995: The rule of halves revisited. J. Hum. Hypertens. 2003, 17, 751-759. [CrossRef] [PubMed]

7. Powietzka, J.; March, S.; Stallmann, C.; Swart, E.; Ladebeck, N. Selected diseases of older employed persons (In German: Ausgewählte Erkrankungen älterer Erwerbstätiger). Zbl. Arbeitsmed. 2016, 66, 331-336. [CrossRef]

8. Van der Niepen, P.; Van De Borne, P.; Persu, A.; Andries, A.; Committee, B.H. Prevalence of hypertension and cardiovascular risk factors in Belgian civil employees: Results of the screening during World Hypertension Day 2007. J. Hypertens. 2008, 26, 1045-1046. [CrossRef]

9. Steiner, S.; Helis, E.; Chen, L.; Turton, P.; Leenen, F.H.; Sonkodi, S.; Sonkodi, B.; D'Angelo, M.S.; Fodor, J.G. A cross-national comparative study of blood pressure levels and hypertension prevalence in Canada and Hungary. J. Hypertens. 2012, 30, 2105-2111. [CrossRef] [PubMed]

10. Lang, T.; de Gaudemaris, R.; Chatellier, G.; Hamici, L.; Diène, E. Prevalence and therapeutic control of hypertension in 30,000 subjects in the workplace. Hypertension 2001, 38, 449-454. [CrossRef]

11. Randerath, O.; Noetel, A.; Möckel, L.; Klinge, M.; Hohlfeld, A.; Eich, S.; Wagner, C.; Kim, J.; Morak, R.; Pychny, J.; et al. In-company blood pressure measurement-A useful preventive measure? Results of a blood pressure measurement campaign in an SME (In German: Innerbetriebliche Blutdruckmessung—eine sinnvolle präventive Maßnahme?). Arbeitsmed. Sozialmed. Umweltmed. 2019, 54, 600-603. Available online: https:/ / www.asu-arbeitsmedizin.com/wissenschaft/ergebnisse-einer-blutdruckmessaktioneinem-mittelstaendischen-unternehmen (accessed on 16 November 2020).

12. Schaller, N.; Blume, K.; Hanssen, H.; Schuster, T.; Schmidt-Trucksäss, A.; Bischof, J.; Halle, M. Prevalence of the metabolic syndrome and its risk factors. Results of a large work-site health assessment. Dtsch. Med. Wochenschr. 2014, 139, $2279-2284$. [CrossRef]

13. Kempf, K.; Martin, S.; Döhring, C.; Dugi, K.; Wolfram von Wolmar, C.; Haastert, B.; Schneider, M. The epidemiological Boehringer Ingelheim Employee study_part I: Impact of overweight and obesity on cardiometabolic risk. J. Obes. 2013, $2013,159123$. [CrossRef]

14. European Communities. Facing the challenge. The Lisbon Strategy for Growth and Employment: Report from the High Level Group Chaired by Wim Kok; Publications of the European Communities: Luxembourg, 2004; ISBN 92-894-7054-2.

15. Robroek, S.J.; van de Vathorst, S.; Hilhorst, M.T.; Burdorf, A. Moral issues in workplace health promotion. Int. Arch. Occup. Environ. Health 2012, 85, 327-331. [CrossRef]

16. Burton, J. WHO Healthy Workplace Framework and Model: Background and Supporting Literature and Practices. 2010. Available online: https:/ / www.who.int/occupational_health/HealthyWorkplaces_Backgrounddoc.pdf (accessed on 16 November 2020).

17. Tautz, A. Company health management (In German: Betriebliches Gesundheitsmanagement). In Prevention and Health Promotion at the Interface between Curative Medicine and Occupational Medicine; Rieger, M.A., Hildebrand, S., Nesseler, T., Letzel, S., Nowak, D., Eds.; A Compendium for Corporate Health Management; Ecomed: Landsberg, Germany, 2016; pp. 23-34. ISBN 978-3-609-10560-4.

18. Drexler, H.; Letzel, S.; Nesseler, T.; Stork, J.; Tautz, A. Occupational medicine 4.0: Theses of the occupational medicine to the conditions and the development need of the workplace health prevention and health promotion in Germany (In German: Arbeitsmedizin 4.0: Thesen der Arbeitsmedizin zum Stand und zum Entwicklungsbedarf der betrieblichen Prävention und Gesundheitsförderung in Deutschland). In (Hrsg.): Prevention and Health Promotion at the Interface between Curative Medicine and Occupational Medicine; Rieger, M.A., Hildebrand, S., Nesseler, T., Letzel, S., Nowak, D., Eds.; A Compendium for Corporate Health Management; Ecomed: Landsberg, Germany, 2016; pp. 333-343. ISBN 978-3-609-10560-4.

19. Petersen, J. Screening examinations in the enterprise (In German: Screeninguntersuchungen im Unternehmen). Arbeitsmed. Sozialmed. Umweltmed. 2010, 45, 22-24. Available online: https:/ /www.asu-arbeitsmedizin.com/sites/default/files/ulmer/deasu/document/file_270849.pdf (accessed on 16 November 2020).

20. Hartmann, B.; Seidel, D.; Hahn, T.; Bräuer, T.; Pieth, J. Results of occupational health service advice on occupational health prevention (In German: Ergebnisse betriebsärztlicher Beratung bei der arbeitsmedizinischen Vorsorge). Arbeitsmed. Sozialmed. Umweltmed. 2007, 42, 236-242.

21. Busch, M. Health behaviour and results of medical examinations of trainee applicants and trainees in a major automotive company (In German: Gesundheitsverhalten und Untersuchungsbefunde von Ausbildungsplatzbewerbern und Auszubildenden in einem Großunternehmen der Automobilindustrie). Arbeitsmed. Sozialmed. Umweltmed. 2007, 42, 606-609.

22. Schneider, M.; Ernsting, A.; Antoni, C.H. Program FIT FOR LIFE_FIT FOR WORK: An effective preventive intervention program for developing a health-promoting lifestyle (In German: FIT IM LEBEN_FIT IM JOB. Eine effektive Maßnahme zum Aufbau eines gesundheitsförderlichen Verhaltensstils). Arbeitsmed. Sozialmed. Umweltmed. 2009, 10, 540-547.

23. Bünger, J.; Lanzerath, I.; Ruhnau, P.; Görlitz, A.; Fischer, C.; Kott, J.; Ellrott, T.; Fiege, A.; Tschentscher, H.; Reutemann, S.K.; et al. Workplace health promotion: Evaluation of interventions to reduce cardiovascular risks (In German: Betriebliche Gesundheitsförderung: Evaluation von Interventionen zur Senkung kardiovaskulärer Risiken). Arbeitsmed. Sozialmed. Umweltmed. 2003, 38, 421-425. 
24. Finell, M.; Weiler, D.; Keskin, M.-C.; Stork, J. General secondary prevention in the operational setting: Example check-up at AUDI. In (Hrsg.): Prevention and Health Promotion at the Interface between Curative Medicine and Occupational Medicine; Rieger, M.A., Hildebrand, S., Nesseler, T., Letzel, S., Nowak, D., Eds.; A Compendium for Corporate Health Management; Ecomed: Landsberg, Germany, 2016; pp. 207-209. ISBN 978-3-609-10560-4.

25. Williams, B.; Mancia, G.; Spiering, W.; Agabiti Rosei, E.; Azizi, M.; Burnier, M.; Clement, D.L.; Coca, A.; De Simone, G.; Dominiczak, A.; et al. ESC/ESH Guidelines for the management of arterial hypertension. The Task Force for the management of arterial hypertension of the European Society of Cardiology (ESC) and the European Society of Hypertension (ESH). EHJ 2018, 39, 3021-3104. [CrossRef]

26. Glynn, L.G.; Murphy, A.W.; Smith, S.M.; Schroeder, K.; Fahey, T. Interventions used to improve control of blood pressure in patients with hypertension. Cochrane Database Syst. Rev. 2010, CD005182. [CrossRef]

27. Visram, S.; Clarke, C.; White, M. Making and maintaining lifestyle changes with the support of a lay health advisor: Longitudinal qualitative study of health trainer services in northern England. PLoS ONE 2014, 9, e94749. [CrossRef]

28. Artinian, N.T.; Fletcher, G.F.; Mozaffarian, D.; Kris-Etherton, P.; Van Horn, L.; Lichtenstein, A.H.; Kumanyika, S.; Kraus, W.E.; Fleg, J.L.; Redeker, N.S.; et al. Interventions to promote physical activity and dietary lifestyle changes for cardiovascular risk factor reduction in adults. A scientific statement from the American Heart Association. Circulation 2010, 122, 406-441. [CrossRef] [PubMed]

29. Miller, W.R.; Rollnick, S. Motivational Interviewing. In Helping People Change (Applications of Motivational Interviewing), 1st ed.; The Gilford Press: New York, NY, USA, 1991.

30. Miller, W.R.; Rollnick, S. Motivational Interwiewing (In German: Motivierende Gesprächsführung): 3rd Edition of the Standard Work in German; Lambertus: Freiburg, Germany, 2015; ISBN 978-3-7841-2545-9.

31. Miller, W.R. Motivational interviewing with problem drinkers. Behav. Psychother. 1983, 11, 147-172. [CrossRef]

32. Lundahl, B.; Moleni, T.; Burke, B.L.; Butters, R.; Tollefson, D.; Butler, C.; Rollnick, S. Motivational interviewing in medical care settings: A systematic review and meta-analysis of randomized controlled trials. Patient Educ. Couns. 2013, 93, 157-168. [CrossRef] [PubMed]

33. Miller, W.R.; Rose, G.S. Toward a theory of motivational interviewing. Am. Psychol. 2009, 64, 527-537. [CrossRef] [PubMed]

34. Miller, W.R. Motivational interviewing: Research, practice, and puzzles. Addic. Behav. 1996, 21, 835-842. [CrossRef]

35. Magill, M.; Gaume, J.; Apodaca, T.R.; Walthers, J.; Mastroleo, N.R.; Borsari, B.; Longabaugh, R. The technical hypothesis of motivational interviewing: A meta-analysis of MI's key causal model. J. Consult. Clin. Psychol. 2014, 82, 973-983. [CrossRef] [PubMed]

36. Eyler, R.; Shvets, K.; Blakely, M.L. Motivational Interviewing to increase postdischarge antibiotic adherence in older adults with pneumonia. Consult. Pharm. 2016, 31, 38-43. [CrossRef]

37. O'Brien, F.; McKee, G.; Mooney, M.; O’Donnell, S.; Moser, D. Improving knowledge, attitudes and beliefs about acute coronary syndrome through an individualized educational intervention: A randomized controlled trial. Patient Educ. Couns. 2014, 96, 179-187. [CrossRef]

38. Tuccero, D.; Railey, K.; Briggs, M.; Hull, S.K. Behavioral health in prevention and chronic illness management: Motivational interviewing. Prim. Car. 2016, 43, 191-202. [CrossRef]

39. Elliot, D.L.; Goldberg, L.; Kuehl, K.S.; Moe, E.L.; Breger, R.K.; Pickering, M.A. The PHLAME (Promoting Healthy Lifestyles: Alternative Models' Effects) firefighter study: Outcomes of two models of behavior change. J. Occup. Environ. Med. 2007, 49, 204-213. [CrossRef] [PubMed]

40. Butterworth, S.; Linden, A.; McClay, W.; Leo, M.C. Effect of motivational interviewing-based health coaching on employees' physical and mental health status. J. Occup. Health Psychol. 2006, 11, 358-365. [CrossRef] [PubMed]

41. Croissant, B.; Hupfer, K.; Löber, S.; Mann, K.; Zober, A. Long-term follow-up on alcohol use in a big company after brief intervention by a company physician (In German: Längsschnittuntersuchung alkoholauffälliger Mitarbeiter in einem Großbetrieb nach werksärztlicher Kurzintervention). Nervenarzt 2008, 79, 80-85. [CrossRef] [PubMed]

42. McPherson, T.L.; Goplerud, E.; Derr, D.; Mickenberg, J.; Courtemanche, S. Telephonic screening and brief intervention for alcohol misuse among workers contacting the employee assistance program: A feasibility study. Drug Alcohol Rev. 2010, 29, 641-646. [CrossRef]

43. Prochaska, J.O.; Butterworth, S.; Redding, C.A.; Burden, V.; Perrin, N.; Leo, M.; Flaherty-Robb, M.; Prochaska, J.M. Initial efficacy of MI, TTM tailoring and HRI's with multiple behaviors for employee health promotion. Prev. Med. 2008, 46, 226-231. [CrossRef]

44. Schneider, R.J.; Casey, J.; Kohn, R. Motivational versus confrontational interviewing: A comparison of substance abuse assessment practices at employee assistance programs. J. Behav. Health Serv. Res. 2000, 27, 60-74. [CrossRef]

45. Adams, A. Prevention of cardio-vascular diseases and diabetes mellitus (In German: Prävention von Herz-KreislaufErkrankungen und Diabetes mellitus). Arbeitsmed. Sozialmed. Umweltmed. 2011, 46, 7-13.

46. Groeneveld, I.F.; Proper, K.I.; van der Beek, A.J.; Hildebrandt, V.H.; van Mechelen, W. Short and long term effects of a lifestyle intervention for construction workers at risk for cardiovascular disease: A randomized controlled trial. BMC Public Health 2011, 31, 836. [CrossRef]

47. Kouwenhoven-Pasmooij, T.A.; Robroek, S.J.W.; Kraaijenhagen, R.A.; Helmhout, P.H.; Nieboer, D.; Burdorf, A.; Hunink, M.G.M. Effectiveness of the blended-care lifestyle intervention 'PerfectFit': A cluster randomised trial in employees at risk for cardiovascular diseases. BMC Public Health 2018, 18, 766. [CrossRef] 
48. Formanoy, M.A.; Dusseldorp, E.; Coffeng, J.K.; Van Mechelen, I.; Boot, C.R.; Hendriksen, I.J.; Tak, E.C. Physical activity and relaxation in the work setting to reduce the need for recovery: What works for whom? BMC Public Health 2016, 16, 866. [CrossRef]

49. Park, J.; Esmail, S.; Rayani, F.; Norris, C.M.; Gross, D.P. Motivational interviewing for workers with disabling musculoskeletal disorders: Results of a cluster randomized control trial. J. Occup. Rehabil. 2018, 28, 252-264. [CrossRef]

50. Boerger, N.L.; Barleen, N.A.; Marzec, M.L.; Moloney, D.P.; Dobro, J. The impact of specialized telephonic guides on employee engagement in corporate well-being programs. Popul. Health Manag. 2018, 21, 32-39. [CrossRef]

51. Verweij, L.M.; Proper, K.I.; Weel, A.N.; Hulshof, C.T.; van Mechelen, W. The application of an occupational health guideline reduces sedentary behaviour and increases fruit intake at work: Results from an RCT. Occup. Environ. Med. 2012, 69, 500-507. [CrossRef]

52. Auer, R.; Gencer, B.; Tango, R.; Nanchen, D.; Matter, C.M.; Lüscher, T.F.; Windecker, S.; Mach, F.; Cornuz, J.; Humair, J.-P.; et al. Uptake and efficacy of a systematic intensive smoking cessation intervention using motivational interviewing for smokers hospitalised for an acute coronary syndrome: A multicentre before-after study with parallel group comparisons. BMJ Open. 2016, 6, e011520. [CrossRef]

53. Härter, M.; Dirmaier, J.; Dwinger, S.; Kriston, L.; Herbarth, L.; Siegmund-Schultze, E.; Bermejo, I.; Matschinger, H.; Heider, D.; König, H.-H. Effectiveness of telephone-based health coaching for patients with chronic conditions: A randomised controlled trial. PLoS ONE 2016, 11, e0161269. [CrossRef]

54. Lin, C.-H.; Chiang, S.-L.; Heitkemper, M.M.; Hung, Y.-J.; Lee, M.-S.; Tzeng, W.-C.; Chiang, L.-C. Effects of telephone-based motivational interviewing in lifestyle modification program on reducing metabolic risks in middle-aged and older women with metabolic syndrome: A randomized controlled trial. Int. J. Nur. Stud. 2016, 60, 12-23. [CrossRef]

55. Steptoe, A.; Kerry, S.; Rink, E.; Hilton, S. The impact of behavioral counseling on stage of change in fat intake, physical activity, and cigarette smoking in adults at increased risk of coronary heart disease. Am. J. Public Health 2001, 91, 265-269. [CrossRef] [PubMed]

56. Van Nes, M.; Sawatzky, J.A. Improving cardiovascular health with motivational interviewing: A nurse practitioner perspective. J. Am. Acad. Nurse Pract. 2010, 22, 654-660. [CrossRef] [PubMed]

57. Woollard, J.; Beilin, L.; Lord, T.; Puddey, I.; MacAdam, D.; Rouse, I. A controlled trial of nurse counseling on lifestyle change for hypertensives created in general practice: Preliminary results. Clin. Exp. Pharmacol. Physiol. 1995, 22, 466-468. [CrossRef] [PubMed]

58. Asayama, K.; Thijs, L.; Li, Y.; Gu, Y.-M.; Hara, A.; Liu, Y.-P.; Zhang, Z.; Wie, F.-F.; Lujambio, I.; Mena, L.J. Setting thresholds to varying blood pressure monitoring intervals differentially affects risk estimates associated with white-coat and masked hypertension in the population. Hypertension 2014, 64, 935-942. [CrossRef] [PubMed]

59. Middeke, M. Hypertension: The Crux of the RR Variability (In German: Hypertonie: Die Krux der RR-Variabilität). Dtsch. Arztebl. 2014, 111, 4. Available online: https:/ / www.aerzteblatt.de/archiv/162154/Hypertonie-Die-Krux-der-RR-Variabilitaet (accessed on 16 November 2020).

60. Slany, K.; Hitzenberger, G.; Zweiker, R.; Mayer, G.; Rosenkranz, A.R.; Watschinger, B.; Wenzel, R. Practical recommendations of the Austrian Society for Hypertensiology (ÖGH) for physician, self and ambulant 24-hour blood pressure measurement (In German: Empfehlungen der österreichischen Gesellschaft für Hypertensiologie (GH) zur Arzt-, Selbst- und ambulanten 24-Stunden- Blutdruckmessung). J. Hyperton. 2008, 12, 13-19.

61. Siu, A.L. Screening for high blood pressure in adults: U.S. Preventive Services Task Force recommendation statement. Ann. Int. Med. 2015, 163, 778-786. [CrossRef]

62. Arain, M.; Campbell, M.J.; Cooper, C.L.; Lancaster, G.A. What is a pilot or feasibility study? A review of current practice and editorial policy. BMC Med. Res. Meth. 2010, 10, 1-7. [CrossRef]

63. Craig, P.; Dieppe, P.; Macintyre, S.; Nazareth, I.; Petticrew, M. Developing and Evaluating Complex Interventions. Medical Research Council. 2019. Available online: https://mrc.ukri.org/documents/pdf/complex-interventions-guidance/ (accessed on 16 November 2020).

64. Eldridge, S.M.; Lancaster, G.A.; Campbell, M.J.; Thabane, L.; Hopewell, S.; Coleman, C.L.; Bond, C.M. Defining Feasibility and pilot studies in preparation for randomized controlled trials: Development of a conceptual framework. PLoS ONE 2016, 11, e0150205. [CrossRef]

65. CONSORT. Extension for Randomized Pilot and Feasibility Trials. Available online: http://www.consort-statement.org/ extensions / overview / pilotandfeasibility (accessed on 16 November 2020).

66. German Hypertension League-German Hypertension Society (Deutsche Hochdruckliga-Deutsche Hypertonie Gesellschaft). Leitlinien zur Behandlung der Arteriellen Hypertonie; AWMF register no. 046/001; German Hypertension League-German Hypertension Society: Heidelberg, Germany, 2008; Available online: http:/ /www.zgk.ch/files/download/206 (accessed on 16 November 2020).

67. Hudak, S. Can Employees with Arterial Hypertension be Motivated to Visit Their Family Doctor by a Motivating Occupational Health Counseling? Study Design and Results of a Feasibility Study (In German: Lassen sich Beschäftigte mit arterieller Hypertonie durch eine motivierende betriebsärztliche Beratung zum Besuch des Hausarztes motivieren? Studiendesign und Ergebnisse einer Machbarkeitsstudie). Ph.D. Thesis, Medical Faculty of the Eberhard Karls University of Tübingen, Tübingen, Germany, 2014. 
68. Frick, K.M.; Brueck, R. Short Interventions with Motivational Interviewing (In German: Kurzintervention mit Motivierender Gesprächsführung); Deutscher Ärzte-Verlag: Köln, Germany, 2009; ISBN 9783769105858.

69. Frick, K. Motivational interviewing-Health-promoting counseling (In German: Motivierende Gesprächsführung-gesundheitsförderlich beraten). In Prevention and Health Promotion at the Interface between Curative Medicine and Occupational Medicine; Rieger, M.A., Hildebrand, S., Nesseler, T., Letzel, S., Nowak, D., Eds.; A Compendium for Corporate Health Management; Ecomed: Landsberg, Germany, 2016; pp. 122-137. ISBN 978-3-609-10560-4.

70. Farian, C.; Michaelis, M.; Schüle, B.; Riedel, M.K.; Rieger, M.A. Repeated blood pressure measurement-Practicability of two methods for the validation of high readings for employees in a company medical setting. Results of a feasibility study (In German: Wiederholende Blutdruck-Messung_Praktikabilität zweier Methoden zur Validierung hoher Messwerte bei Beschäftigten im werksärztlichen Setting. Ergebnisse einer Machbarkeitsstudie). In Proceedings of the 58th Congress of the Society for Work Science (GfA), Kassel, Germany, 22-24 February 2012; GfA-Press: Dortmund, Germany, 2012; pp. 923-926.

71. Keil, U.; Fitzgerald, A.P.; Gohlke, H.; Wellmann, J.; Hense, H.-W. Risk assessment of fatal cardiovascular diseases. The new SCORE Germany Tables for primary prevention (In German: Risikoabschätzung tödlicher Herz-Kreislauf-Erkrankungen: Die neuen SCORE-Deutschland-Tabellen für die Primärprävention). Dtsch. Arztebl. 2005, 102, 1808-1812. Available online: https: / / www.aerzteblatt.de/archiv/47409/Risikoabschaetzung-toedlicher-Herz-Kreislauf-Erkrankungen-Die-neuen-SCOREDeutschland-Tabellen-fuer-die-Primaerpraevention (accessed on 16 November 2020).

72. Donabedian, A. The definition of quality and approaches to its assessment. In Explorations in Quality Assessment and Monitoring; Health Administration Press: Chicago, IL, USA, 1980; Volume I.

73. Bühner, M.; Ziegler, M. Statistics for Psychologists and Social Scientists; Pearson (in German Statistik für Psychologen und Sozialwissenschaftler): Munic, Germany, 2009.

74. Seibt, R.; Naumann, H.-J.; Hinz, A. Evaluation criteria of blood pressure self-measurement and 24-hour blood pressure measurement (In German: Bewertungskriterien der Blutdruckselbstmessung und der 24-Stunden-Blutdruckmessung). NierenHochdruckkrankh 1996, 25, 337-340.

75. Seibt, R.; Hunger, B.; Stieler, L.; Stoll, R.; Kreuzfeld, S. Early Detection of Undiagnosed Hypertension Based on Occupational Screening in the Hotel and Restaurant Industry. Biomed Res. Int. 2018, 6820160. [CrossRef] [PubMed]

76. Brueck, R.; Frick, K.; Loessl, B.; Kriston, L.; Schondelmaier, S.; Go, C.; Härter, M.; Berner, M. Psychometric properties of the German Version of the Motivational Interviewing Treatment Integrity Code (MITI-d). J. Subst. Abuse Treat. 2009, $36,44-48$. [CrossRef] [PubMed]

77. Jarbøl, D.E.; Larsen, P.V.; Gyrd-Hansen, D.; Søndergaard, J.; Brandt, C.; Leppin, A.; Barfoed, B.L.; Nielsen, J.B. Determinants of preferences for lifestyle changes versus medication and beliefs in ability to maintain lifestyle changes. A population-based survey. Prev. Med. Rep. 2017, 6, 66-73. [CrossRef] [PubMed] 